\title{
ETS Translocation Variant 5
}

National Cancer Institute

\section{Source}

National Cancer Institute. ETS Translocation Variant 5. NCI Thesaurus. Code C97481.

ETS translocation variant 5 (510 aa, $\sim 58 \mathrm{kDa}$ ) is encoded by the human ETV5 gene. This protein plays a role in the regulation of transcription. 